\title{
Self-confidence as an intermediary variable between psychological empowerment and job burnout among special education teachers in Gaza governorates
}

\author{
Najah Awad El-Smairy \\ Associate Professor of Mental Health, Department of Psychology, Al-Aqsa University - Gaza
} na.alsumiry@alaqsa.edu.ps 


\section{Self-confidence as an intermediary variable between psychological empowerment and job burnout among special education teachers in Gaza governorates}

\section{Najah Awad El-Smairy}

Associate Professor of Mental Health, Department of Psychology, Al-Aqsa University, Palestine na.alsumiry@alaqsa.edu.ps

Received: 10-2-2021 Revised: 29-5-2021 Accepted: 1-9-2021 DOI: https://doi.org/10.31559/CCSE2021.3.1.1

\section{Abstract:}

The present study aimed to establish a theoretical model for the causal relationship between the three variables of study: self-confidence, psychological empowerment and job burnout; and then verify the validity of the proposed model by examining the direct and indirect impact of selfconfidence on both psychological empowerment and job burnout; and determine the nature of the course of their relationship; and to see if self-confidence is mediator variable in the relationship of psychological empowerment and job burnout. The study sample consisted of (140) teachers from special needs teachers and used the following questionnaires: selfconfidence, psychological empowerment and job burnout that prepared by the researcher. Results of the study indicate that there is a positive relationship between self-confidence and psychological empowerment, and a negative relation between self-confidence and job burnout, and a negative relationship between psychological empowerment and job burnout. Results of the regression analysis showed that self-confidence and psychological empowerment contribute to the prediction of job burnout, and the results of the study showed that self-confidence plays the role of the partial mediator variable in the relationship between psychological empowerment and job burnout among teachers of special education in Gaza governorates.

Keywords: psychological empowerment; job burnout; special education; Gaza.

\footnotetext{
${ }^{*}$ Corresponding author

Najah Awad El-Smairy

Associate Professor of Mental Health, Department of Psychology, Al-Aqsa University, Palestine

E-mail: na.alsumiry@alaqsa.edu.ps
} 


\section{Introduction}

Special education institutions, like general education institutions, has been witnessing many challenges in light of the successive changes currently taking place in educational, educational and administrative thought. This was clear since the end of the twentieth century witnessed a knowledge revolution adopted by many advanced countries in the field of human, cognitive and educational sciences, which provided the opportunity for researchers to address this knowledge. In addition, the concepts from the scientific cognitive perspective according to the philosophy of society and its objectives, and among the most prominent of these concepts is what is related to the psychological cognitive construction that is related to the human being and its construction, and empowerment based on successive variables like other building elements. Also, the empowerment is considered as a general term related to ability and competence within the limits of knowledge, while it comes in the direction of psychological construction and empowering the individual psychologically so that he can create and innovate to occupy a position distinguished status and position among others.

Bakhit, 2008 states that empowering the employee means that we improve his ability to make decisions by himself and without directing the management. The primary goal of empowerment is to provide conditions to allow all employees to contribute to their maximum potential in the efforts of creativity and continuous improvement, and therefore the term empowerment includes the participation of the process of taking the decision with other administrative levels, represented by the powers of more than just delegation, and the employee also feels.
Responsibility for actions outside the boundaries of his job, so that the whole organization works more responsibly (quoted from Afaneh, 2013,3).

Psychological empowerment is positively and closely related to the concept of self-confidence and is considered an important and effective input in continuous promotion and development, and in increasing selfefficacy, creativity, creative thinking, selfmotivation, participation and expressing opinion, and building confidence among superiors and subordinates, as well as an important means that can be invested and employed in unleashing the capabilities of creative and creative workers, providing more satisfaction, and a positive attitude towards life, which enables them to gain a greater sense of competence and achievement. Self-confidence and a positive attitude towards life are among the most important outcomes of psychological empowerment. Clearly, there is a sense of the value and meaning of work, a sense of competence, freedom of action, participation and independence are among the factors that lead to the individual's feeling of his worth and his job (Al-Nawajhah, 2015, 288).

Empowerment is also a phenomenon that includes many elements of internal motivation because it is one of the most important outcomes of the decisions taken by the individual in his field of work, which reflects on him by enhancing his motivation towards work, empowering the individual in his field of work and the ability to influence the activities of the work environment in all its details. On this basis, psychological empowerment is not just an individual feeling that is unique to workers only within any institution, whether educational or service, but rather requires structural elements and appropriate organizational 
factors, as well as the suitability of the network of relationships between members of a single work organization represented by the director, his assistants, and his workers in various job titles. In addition to the administrative, on the basis of trust, support and constructive communication, providing employees alike with all the necessary information they need It is not necessary for the individual to feel responsible for the work within his team. Apparently, trust increases a person's sense of his value, and the more his self-confidence increases, the more he becomes a person who behaves normally without worry or fear, because he is the one who controls his behavior and not others, and we find the opposite, "lack of confidence" that makes a person act in an unnatural way and feels that he is being watched by those around him, so his movements and opinions are contrary to him. Because of his nature, anxiety becomes inherent in all of his works (AlWashli, 2007, 3).

If looked at the educational institution in general as one of the effective organizational institutions in building and preparing the individual to be good in the society, it is clear that the teacher plays a fundamental role in this construction, and therefore the special education teacher is considered to reserve the corner in the education, education and rehabilitation of persons with disabilities, and therefore the process of choosing them. This increasingly burdensome task is an important process, as he is entrusted with arduous tasks through dealing with a private class of students, who need much effort and time in carrying out an educational task, and according to the continuous increase in the number of the disabled, the need for a special education teacher has increased in all schools. Basic education, hence, the importance of choosing a special education teacher, in terms of the availability of distinct professional qualities, characteristics and personality traits that may not be available in the ordinary teacher. This is to achieve the general educational objective of the institution in which he works, for all students with disabilities.

Perhaps working with persons with disabilities comes at the forefront of professions that can create feelings of frustration among workers, given the requirements of these professions with the requirements of various categories of extraordinary people, who suffer from mobility, mental, auditory, and visual disabilities, or multiple disabilities. Every person with a disability is a special case that requires a special type of service, education, training and support, in addition to the low capabilities of persons with disabilities and the variety of their problems and their severity at times may generate among many of those working with them a feeling of frustration, and a weak sense of achievement or success, which will lead. These workers feel psychological and occupational pressures, which stop and decrease according to the personality characteristics of those working with this group.

In many professions, especially professions of a humanitarian and cooperative nature, various obstacles and pressures may appear that prevent the employee from performing his required role as he and others expect it.

Al-Nafiei, 2001 considers the phenomenon of job burnout as one of the most prominent obstacles that may appear in the field of work with persons with disabilities. On the other hand, it is one of the most important institutional organizational phenomena that limit the capabilities of workers, their development and self-confidence, and negatively affect their job performance, and thus affect in the performance and production of the institution, and accordingly the issue of 
job burnout has gained great importance to writers and researchers in the developed countries during the past three decades. This is not only in the field of organizational behavior and medical science, but also in the field of administrative development because it is one of the important administrative problems in our contemporary world that face workers in organizations Governmental and non-governmental alike. One of the important concepts is that it is based on the human resource, which is the pillar of development and progress In any organization, its absence is considered an indication of the organizations going through a crisis that could lead to decline, decline and failure in the long term due to the negative effects on organizations and their workers (Masoud, 2010, 2).

In the same context, the sense of the workers of different groups, especially the special education teachers, that they are dealing with a group of students with different psychological, physical, mental, and educational characteristics than others through job burnout means their loss of self-confidence and their inability to control the events surrounding them. Moreover, the sense of meaninglessness or the absence of a specific goal for them, as well as the feeling the difference between the goals and the appropriate means to achieve them. In addition, social isolation, and alienation from oneself, leading to a lack of psychological empowerment, all of which reinforce the negative side in performance and the failure of the institution caring for people with disabilities later. Self-confidence is considered one of the most important emotional features that an individual acquires from the social environment in which he lives and deals with it. Confidence increases a person's sense of the value, and the more the selfconfidence increases, he/she becomes a person who behaves naturally without anxiety or fear. $\mathrm{He} / \mathrm{she}$ is the one who controls his/her behavior and not others, and we find the opposite. Trust "makes a person act in an abnormal way and feel that he is being watched around him/her, so his/her movements and opinions contradict his/her nature and anxiety becomes inherent to him/her in all his actions. Self-confidence is the key to success in a person's life in general and the life of a teacher, because without it, he/she will not be able to achieve his goals and will not excel professionally or in life. Chang, C., and W. Cheng. 2008 emphasized the positive correlation between self-confidence and superior life in general, with its many variables affecting the individual's performance and behavior.

The importance of self-confidence also stems from the premise that no one should dispense with it. A person with low self-confidence is a person who is vulnerable to many disorders for two reasons: The first is that he/she does not trust his/her information or opinions, he/she will not be able to debate and dialogue with others and he/she will prefer silence. The second reason is that he/she will believe All that is said about him/her in the negative, as for the positive, he/she will take it on the burden of mockery or that it is a compliment that has no basis in reality, which means that he will not be able to achieve any point of success or starting in his field of work, and if he achieves any of them, he will not feel the pleasure of joy and success, and this in turn will make him/her live in an atmosphere of boredom, depression, and thus burning, and he/she prefers to avoid people to avoid their criticism of him/her and their sarcastic comments about his/her condition, and his/her belief that he/she is not liked by them and that he/she is a person of lesser than them. This continuous avoidance will deprive its 
owner from acquiring life experiences, which reduces or negates the effectiveness of his/her empowerment and his/her inner fortitude in the face of difficulties, and the individual may take a course against isolation, which is aggression strongly against others, and this is an unconscious behavior to preserve himself so that his/her weakness is not revealed and his/she situation becomes clear, and both cases mean An abnormal condition that needs to be intervened to fix it and bring it back to the straight line (Ali, 2009: 26).

There are several studies that have dealt with this topic with research, including the study of Al-Anzi (2001), the results of which resulted in the presence of four sub-factors that make up trust (selfreliance, reluctance in decision-making, generalization and management, and selfconfidence in social situations), and no significant differences were found. In the self-confidence of the sexes. Shelton's (2002) study revealed the necessity of building confidence in an employee before embarking on empowerment to their success. Kharabsheh and Arabiyat (2005) showed that the degree of psychological burnout among teachers working with students with learning difficulties was moderate on the two dimensions of emotional stress and emotions dulled, and to a high degree on the dimension of lack of sense of achievement. Al-Qaryouti and Al-Khatib (2006) showed that there are differences in psychological burnout for the benefit of the teachers of the visually impaired and the gifted compared to the teachers of the ordinary students, and in the interest of the teachers of the disabled students visually, a comparison with the teachers of students with hearing impairments, mobility and those with multiple disabilities, and in the interest of the teachers of the hearing impaired and the deaf, compared to the teachers of mentally handicapped and mentally challenged students. Awwad's study (2009) showed that the burnout rate among primary school teachers resulting from the integration of students with special needs into regular classes is average, and the study results showed that there is not the existence of differences according to the sex variables, academic qualification, experience and interaction between them. Al-Nuri (2011) study also showed that there are differences in the dimensions of psychological burnout due to a variable (gender, age, academic rank, and specialization). Al-Batayneh and AlShaher (2012) showed a positive relationship between social support and psychological burnout. The results also showed that there are differences in both social support and psychological burnout due to age, gender, and experience. Tashoush, Jarwan, Muhaidat and Benny (2013) found that the level of psychological burnout and job satisfaction among resource room teachers was average, and there was an inverse relationship between psychological burnout and job satisfaction, and the results pointed that teachers with master's degrees have a high level of psychological burnout Whereas, BA teachers have a higher level of job satisfaction. The results of a study have indicated Al-Lalla Alala (2014) indicates a high level of psychological burnout in the two dimensions of lack of a sense of achievement and dullness of feelings, and a medium level in the dimension of emotional stress in the study sample, and to the absence of differences between the teacher's specialization and after emotional stress, and the presence of differences between the teacher's specialization and after the lack of a sense of achievement, and dullness emotions among teachers of students with special needs, Orly Shapira (2014) revealed that the psychological variable is a mediating 
variable between teachers' perceptions of real leadership and organizational behaviors. Also, Shaheen (2015) revealed that there are differences in combustion in favor of low empowerment, while no differences in psychological empowerment appeared due to the variable of gender, experience and interaction between them, and differences in combustion attributed to sex in favor of females were also found. While there are no differences attributed to the variable experience. Mirzaie (2015) revealed that professional counseling has a significant impact on the psychological empowerment of female teachers. Othman and Barakat (2016) declared that there was a statistically significant relationship between the dimensions of psychological empowerment, academic and self-efficacy. Additionally, Aghaei, Savari(2016) stated that there is a relationship between psychological empowerment and professional commitment, and it has shown the possibility of predicting professional commitment through psychological empowerment. It is evident from previous studies that they dealt with important psychological variables worthy of research in the field of mental health, as it showed the importance of self-confidence, psychological empowerment, and job burnout among education teachers. In addition, its relationship to important aspects, including shyness, empowerment perception, social support, job satisfaction, self-efficacy, professional commitment, and others. Some studies have also unanimously agreed on the importance of self-confidence and psychological empowerment in improving Mental health and the reduction of job burnout. This study was distinguished from previous studies in that it specifically dealt with special education teachers in the governorates of Gaza, especially in light of the remarkable increase in numbers, preparation, and rehabilitation of the Palestinian society, and they have aspirations towards their profession and towards the group of students with whom they deal disability. This qualifies them to take more active roles in the development of society, advancing development on the one hand, improving their condition, and empowering them psychologically and professionally, and then professionally, economically and socially in the future, and realizing themselves. It turned out that after a review psychological literature the scarcity of Palestinian studies, and Arab and foreign studies in general that dealt with the variables of the current study within the limits of the studies available to the researcher, which highlights its research importance. It could also be the start of an organized research effort in the field of special education teachers from various aspects, and then prepare psychological measures for this important segment in the educational community. It should also be noted that the researcher benefited from previous studies in defining the study problem and its objectives, formulating hypotheses, preparing measures, and then interpreting the results. Based on the above and the importance of both psychological empowerment and job burnout in the field of special education, the researcher chose them with the aim of revealing selfconfidence as a mediating variable between psychological empowerment and professional burnout among special education teachers. This study was distinguished from previous studies that it specifically dealt with special education teachers in the governorates of Gaza, especially in light of the remarkable increase in numbers, preparation and rehabilitation of Palestinian society, and they have aspirations towards their profession and towards the group that they deal with from among students with disabilities, in order to qualify them to 
take effective roles. Also, to enhance development means improving their condition and empowering them psychologically and functionally, and then professionally, economically, and socially in the future, and realizing themselves. It also became clear that after reviewing the psychological literature, the scarcity of Palestinian studies, and Arab and foreign studies in general that dealt with the variables of the current study within the limits of the researcher's availability studies that highlight its research importance. It can also be the starting point for an organized research effort in the field of special education teachers from various aspects, then preparing psychological measures for this important segment in the educational community. It should also be noted that the researcher benefited from previous studies in defining the study problem and its objectives, formulating hypotheses, preparing measures, and then interpreting the results. Accordingly, the researcher chose them with the aim of uncovering self-confidence as a mediating variable between psychological empowerment and professional job burnout among special education teachers.

\section{The Study Problem:}

The problem of the current study is to investigate the effect of psychological empowerment on occupational burnout among special education teachers, and the role that another psychological variable can play in mediating between both psychological empowerment and professional job burnout. The researcher proposed a causal model. The study problem is determined in the following main question: Could self-confidence be a mediating variable in the relationship between psychological empowerment and professional burnout among special education teachers?

\section{Objectives of the Study:}

The present study aims to identify the size of the correlation between psychological empowerment and both selfconfidence and professional burnout among special education teachers. Also, it aims to investigate the extent of psychological empowerment contributes to predicting the degree of self-confidence and professional burnout among special education teachers. In addition, it seeks for identifying the extent to which selfconfidence contributes to predicting professional burnout among special education teachers. As well as identifying the role of statistical isolation of the effect of self-confidence degrees on the relationship between psychological empowerment and professional career burnout in the presence of the relationship.

\section{The Importance of Study:}

The importance of the theoretical study is due to the importance of the topic that the researcher dealt with, as it focuses on self-confidence as a mediating variable in the relationship between psychological empowerment and occupational burnout among special education teachers, and then this study comes in the direction of modern psychological studies and research, and there is no doubt that this topic involves a wide measure of importance stems from the importance of its variables, self-confidence in general, and as a mediating variable in particular, psychological empowerment, and professional job burnout because of their importance in the teaching and learning process, as the psychological literature has indicated the importance of psychological empowerment and professional career burnout in shaping teacher behavior. Moreover, building trends towards the teaching profession, and these variables within the limits of the researcher's 
knowledge, local and Arab studies did not address them together with research, especially among an important segment that has both educational and psychological specificity in the field of special education, namely, a segment of special education teachers.

As for the practical importance of the study, i may contribute in providing psychometric tools suitable for the local and Arab libraries that can be referred to and trusted in measuring the variables of self-confidence, psychological empowerment, and job burnout, and it can also encourage future use by specialized researchers, and it may contribute in helping teachers of special education, and workers in the educational field at the governmental and private levels, by providing them with some methods that help them in reducing or reducing professional job burnout. By emphasizing the role of self-confidence as a positive variable that contributes to enhancing psychological empowerment and reducing the impact of job burnout, as well as directing interested people and researchers towards designing counseling programs to improve the self-confidence of special education teachers with the aim of raising psychological empowerment and reducing occupational burnout to improve the level of education for people with needs Own.

\section{Study terms:}

\section{First: Self-confidence:}

Self-confidence is the individual's view of himself/herself and others or his/her belief in his/her ability to support his/her social position and his feeling of happiness and tranquility.

The level of self-confidence is measured procedurally by the total score obtained by the respondent through his response to the paragraphs of the selfconfidence scale prepared by the researcher, which ranges between (21-63) degrees.

\section{Second: Psychological Empowerment:}

Psychological empowerment idiomatically as: the motivational or psychological element that appears through five dimensions, namely: (the importance of work, and it is intended for the individual's perception of the feasibility of work through the compatibility of his beliefs and values with the requirements of the work) and (influence and is intended by the individual's perception of the extent of his influence on his work activities, And on the strategic administrative or operational results at work (and) professional competence, which means the individual's perception of his competence and his aptitude through possessing the ability and skill to accomplish the tasks assigned to him with the required effectiveness) and (independence) and is meant by the individual's awareness of his freedom in the report of completion

His/her work, choosing the appropriate alternatives and setting standards of behavior in proportion to his/her appreciation and his/her own point of view) and (self-efficacy, which means the individual's awareness of the beliefs and ideas he possesses about himself/herself, his/her potentials and abilities, which determine in the future his/her behaviors that he will have in the future), and these five dimensions with Each other plays a positive, not a negative, role in directing teachers in particular towards their role in the teaching profession. The level of psychological empowerment is measured procedurally by the overall degree obtained by the respondent through his response to the paragraphs of the psychological empowerment scale prepared by the researcher, ranging between (54-162) degrees. 
International Journal of Childhood, Counselling, \& Special Education (CCSE), Volume3, Issue1, Sept: 2021, pp.1-19

\section{Third: Professional Occupational Burnout:}

Occupational burnout idiomatically is a group of symptoms of psychological stress, emotional exhaustion, personal indolence, and a sense of dissatisfaction with personal achievement and professional performance. The level of occupational burnout is measured procedurally by the overall degree obtained by the respondent through his response to the paragraphs of the Occupational Burnout Scale prepared by the researcher, ranging between (46-138) degrees.

\section{Fourth: The Intermediate variable:}

The intermediate variable mediates the relationship between two variables, one of which is the independent variable and the other the dependent variable, and answers one of the two questions: How does the effect of the independent variable occur on the dependent variable? or why is the dependent variable affected by the independent variable? Then the mediating variable is treated because of the independent variable, and a cause at the same time for the dependent variable and another predictor of it, and accordingly, the strength of the effect that the independent variable has on the outcome may decrease in its statistical significance or disappear completely when the mediating variable is controlled and adjusted in The Proposed Causal Model. "

\section{Limitations of the Study:}

Self-confidence as intermediate
variable between empowerment and professional job burnout among special education teachers in Gaza governorates. Concerning the approach, the descriptive and correlational approach was followed, because of its suitability for the nature of the study and its objectives, where the researcher aimed to identify the significance of the causal relationships between the study variables to reach a supposed causal model through which the direct and indirect effects of the relationship of a self-confidence in both psychological empowerment and professional job burnout, and in the sample used in the study, which is (103) teachers of special education teachers in the Gaza governorates, of whom (43) males and (60) females, and with the tools used, which are a measure of: selfconfidence, empowerment. The psychological and occupational burnout was prepared by the researcher, and with the statistical methods used, namely: Pearson Correlation Coefficient, and simple and multiple regression analysis.

\section{Study Participants:}

The study population consisted of all the special education teachers working in governmental and private institutions, whose number is (176) teachers, according to the statistics of the Special Education Department of the Ministry of Education Gaza for the 2015/2016 academic year.

The researcher distributed (180) questionnaires to all these institutions, and (128) teachers responded, and after reviewing the questionnaires, only (140) questionnaires were valid for analysis, and they represent $(85.46 \%)$ of the study population. Thus, the study sample consisted of (103) male and female teachers, of whom (60) are males, and (80) females are distributed over all these institutions.

\section{Methods}

\section{1) The Self-Confidence Scale:}

The questionnaire was presented to a group of experts and specialists in education and psychology in order to know their opinions on "self-confidence in special education teachers." to achieve this purpose purpose, the researcher 
designed the questionnaire, and then calculated the extent of agreement of each paragraph of the questionnaire with the questionnaire as a whole, and in light of the opinions of the judges, some paragraphs were excluded and others were amended to make the number of paragraphs of the questionnaire (21) paragraphs. In order to obtain the equal weights of the paragraphs of the questionnaire, the estimates were given (1, $2,3,4)$ for the four-degree scale and the four-alternative scale (strongly agree, agree, disagree, strongly disagree), where the total score of the resolution ranged between (21-84) degrees. The formative validity of the questionnaire was also ascertained by calculating the correlation coefficients between the score of each of the paragraphs

The questionnaire was implemented on a sample of (30) special education teachers from outside the study sample, and the correlation coefficients for the items of the questionnaire and the total degree of the resolution ranged between $(0.61$ - 0.81), which are statistically significant correlation coefficients at the level (0.01), which indicates enjoyment The questionnaire is of high accuracy. The researcher also calculated the discriminatory validity of the scale, where the value of "T" for the differences between the upper and lower groups reached (9.5), which is a statistically significant value at the level of 0.01 .

The stability of the resolution was also calculated, using the internal consistency method (Cronbach Alpha), where the reliability coefficient reached (0.76), which is a reliability coefficient indicating high stability of the resolution. The researcher also calculated the stability by re-testing after three weeks had passed again on the same sample. The correlation coefficients between the two applications reached (0.86), which is a significant correlation coefficient at a significance level of 0.01 .

\section{2) Psychological Empowerment Scale}

The questionnaire was presented to a group of experts and specialists in education and psychology in order to know their opinions views on "psychological empowerment among special education teachers." to achieve this purpose, the two researchers constructed the questionnaire, and then calculated the extent to which each paragraph of the questionnaire agreed with the questionnaire as a whole, and in light of the opinions of the arbitrators Gentlemen, some paragraphs were excluded and others were amended to make the number of paragraphs of the questionnaire (54) paragraphs. In order to obtain the equal weights of the paragraphs of the questionnaire, estimates were given $(1,2,3,4)$ for the four-degree scale and the four-alternative scale (strongly agree, agree, disagree, strongly disagree), where the total score for the resolution ranged between (54-216) degrees.

The formative validity of the questionnaire was also confirmed, by calculating the correlation coefficients between the degree of each paragraph of the questionnaire and the total degree of the questionnaire, on a sample of (30) special education teachers from outside the study sample, and the correlation coefficients for the paragraphs of the questionnaire and the total degree of the resolution ranged between $(0.59-0.86)$ They are statistically significant correlation coefficients at the level (0.01), indicating that the questionnaire enjoys high validity. The researcher also calculated the discriminatory validity of the scale, where the value of " $\mathrm{t}$ " for the differences between the upper and lower groups reached (10.5), which is a statistically significant value at the level of 0.01 
The stability of the resolution was also calculated using the internal consistency method (Cronbach Alpha), where the reliability coefficient was (0.80), which is a reliability coefficient indicating a high stability of the resolution.

The researcher also calculated the stability by re-testing after three weeks passed again on the same sample. The correlation coefficients between the two applications reached (0.80), which is a significant correlation coefficient at a significance level of 0.01 .

\section{3) Professional Occupational Burnout Scale}

The researcher presented the questionnaire to a group of experts and specialists in education and psychology to know their views on "professional burnout among special education teachers.” For this purpose, researcher constructed the questionnaire, and then calculated the extent to which each paragraph of the questionnaire agreed with the questionnaire, and in light of Opinions of the arbitrators, some paragraphs were excluded, and others were amended to make the number of paragraphs of the questionnaire (46) paragraphs. In order to obtain the equal weights of the paragraphs of the questionnaire, the estimates were given $(1,2,3,4)$ for the four-degree scale and the four-alternative scale (strongly agree, agree, disagree, strongly disagree), where the total score of the questionnaire ranged between (46-184) degree.

The formative validity of the questionnaire was also ascertained by calculating the correlation coefficients between the degree of each paragraph of the questionnaire and the total degree of the questionnaire, on a sample of (30) special education teachers from outside the study sample, and the correlation coefficients for the paragraphs of the questionnaire and the total degree of the questionnaire ranged between ( 0.65 .
0.88), which are statistically significant correlation coefficients at the level (0.01), which indicates that the questionnaire has high validity. the discriminatory validity of the scale was calculated, as the value of " $t$ " for the differences between the upper and lower groups reached (7.5), which is a statistically significant value at the level of 0,01 . The stability of the resolution was also calculated, using the internal consistency method (Cronbach Alpha), where the reliability coefficient was (0.88), which is a reliability coefficient indicating high stability of the resolution. the researcher also calculated stability by retesting after three weeks passed again on the same sample, the correlation coefficients between the two applications reached (0.82), which is a significant correlation coefficient at a significance level of 0.01 .

\section{Statistical treatment:}

To achieve the objectives of the study and testing its hypotheses, the researcher used the following statistical methods: Simple Pearson Correlation Coefficient to identify the nature of the relationship between psychological empowerment and each of self-confidence and occupational burnout. The Simple Regression analysis to identify the possibility of predicting selfconfidence and psychological empowerment in occupational burnout among special education teachers. Multiple regression coefficient to identify the nature of the true relationship between psychological empowerment and occupational burnout after statistical isolation of the impact of self-confidence, by using the method of path analysis.

\section{Results and interpretation of the study}

To answer the study's questions, the researcher constructed a proposed causal model based on a theoretical basis that the 
researcher reached through the theoretical framework and previous studies related to the subject of the study. After that they tested the validity of the model, shown in Figure (1) where the direct effect of psychological empowerment on combustion is evident. Occupational career, as the indirect effect is evident by adding self-confidence as an intermediate variable to the regression equation in the causal model. To verify the validity of the model, the researcher used the path analysis method, which is a method used to identify the trends of influence between the study variables through a causal model that organizes the relationship between the variables Independent and dependent study.

And in this regard, the third question states: What is the role of self-confidence as an intermediating variable in the relationship between psychological empowerment and professional burnout? To answer this question, the researcher built a proposed causal model, and then tested the validity of this model. To verify the validity of the proposed model, the researcher used the path analysis method to study self-confidence as an intermediate variable in the relationship between psychological empowerment and occupational burnout, using (Process Macro) Added to the SPSS Statistical Package for Human Sciences, where the hypothesis was tested according to the following steps as defined by Hayes, 2013:
1. Conducting a simple regression test between the independent variable and the mediating variable.

2. Conducting a test simple regression between the intermediate variable and the dependent variable.

3. Perform a simple regression test between the independent variable and the dependent variable. Path analysis to reveal the intermediate relationship of the study variables by using (Process Macro) added to the SPSS statistical package. Four secondary questions are divided into this question: Based on the above, the verification of the previous conditions is done through the researcher's presentation of the statistical results related to the study questions on Towards the next:

\section{The first question stated:}

A- What is the size of the correlational relationship and its statistical significance between the measure of selfconfidence and psychological empowerment of special education teachers in the Gaza governorates

To verify the answer to this question; The researcher used the Pearson correlation coefficient to identify the relationship between psychological empowerment and self-confidence, and the researcher obtained the results shown in the following table:

Table (1): A- Correlation coefficients between the two measures of self-confidence and psychological empowerment of special education teachers in the Gaza governorates.

Total score of Psychological Empowerment Scale

\begin{tabular}{|c|c|c|c|c|c|c|}
\hline Statement & $\begin{array}{l}\text { The } \\
\text { importance of } \\
\text { working }\end{array}$ & $\begin{array}{l}\text { the } \\
\text { influence }\end{array}$ & Professionalism & Independence & $\begin{array}{l}\text { Self- } \\
\text { efficacy }\end{array}$ & $\begin{array}{l}\text { Overall score on } \\
\text { the Psychological } \\
\text { Empowerment } \\
\text { Scale }\end{array}$ \\
\hline $\begin{array}{l}\text { The overall score } \\
\text { for the Self- } \\
\text { Confidence } \\
\text { Scale }\end{array}$ & $0.94^{* *}$ & $0.98^{* *}$ & $0.94^{* *}$ & $0.95^{* *}$ & $0.92^{* *}$ & $0.82^{* *}$ \\
\hline
\end{tabular}


The previous table shows that there is a positive relationship between the two measures of self-confidence and psychological empowerment among special education teachers in the Gaza governorates.

The researcher believes that this result is natural, as the teacher who has selfconfidence is certain of this confidence he derived from the degree of his mastery in his specialization, his teaching methods. Among the characteristics of selfconfidence is that it stimulates positive emotions, gives rise to a feeling of enthusiasm and joy, helps focus attention, increases perseverance and effort in order to achieve goals and success, which contributes to building a positive concept, making the individual comfortable, free of fears, able to organize the environment and his ideas quickly and accurately and with less help from others than Enables him to overcome difficulties and reach a high level of achievement and this eagerness to discuss with others and selfesteem (El-umar, 2000, 83-88).

The second question "What is the size of the correlation and its statistical significance between psychological empowerment and professional burnout among special education teachers in Gaza governorates?"

And to answer this question; The researcher used the Pearson correlation coefficient to reveal the relationship between psychological empowerment and occupational burnout, and the researcher obtained the results shown in the following table:

Table (2): Correlation coefficients between the two measures of psychological empowerment and occupational burnout

\begin{tabular}{|c|c|c|c|c|c|c|}
\hline Statement & $\begin{array}{l}\text { Job } \\
\text { dissatisfaction }\end{array}$ & $\begin{array}{l}\text { Negative } \\
\text { trend } \\
\text { towards } \\
\text { students } \\
\text { with } \\
\text { special } \\
\text { needs }\end{array}$ & $\begin{array}{l}\text { Personal lack } \\
\text { of } \\
\text { achievement }\end{array}$ & $\begin{array}{l}\text { Occupational } \\
\text { pressure }\end{array}$ & $\begin{array}{l}\text { Lack of } \\
\text { positive } \\
\text { reinforcement }\end{array}$ & $\begin{array}{l}\text { The overall } \\
\text { score of the } \\
\text { Occupational } \\
\text { Occupational } \\
\text { Burnout } \\
\text { Scale }\end{array}$ \\
\hline $\begin{array}{l}\text { The importance } \\
\text { of working }\end{array}$ & ${ }^{* *} 0.472$ & $* * 0.250$ & ${ }^{* *} 0.345$ & ${ }^{* *} 0.71-$ & **0.65- & ${ }^{* *} 0.408$ \\
\hline the influence & **0.498 & **0.419- & ${ }^{* *} 0.400$ & ${ }^{* *} 0.45$ & ${ }^{* *} 0.78$ & ${ }^{* *} 0.501-$ \\
\hline Professionalism & $* * 0.594$ & ${ }^{* *} 0.356-$ & ${ }^{* *} 0.438$ & ${ }^{* *} 0.66-$ & ${ }^{* *} 0.66-$ & $* * 0.531-$ \\
\hline Independence & ${ }^{* *} 0.448$ & **0.398- & ${ }^{* *} 0.380$ & $* * 0.56$ & ${ }^{* *} 0.54$ & ${ }^{* *} 0.475$ \\
\hline Self-efficacy & ${ }^{* *} 0.54$ & **0.65- & ${ }^{* *} 0.42-$ & ${ }^{* *} 0.33-$ & ${ }^{* *} 0.67-$ & ${ }^{* *} 0.400$ \\
\hline $\begin{array}{l}\text { Total Degree } \\
\text { Empowerment }\end{array}$ & ${ }^{* *} 0.627$ & ${ }^{* *} 0.462-$ & ${ }^{* *} 0.489$ & ${ }^{* *} 0.49$ & ${ }^{* *} 0.67-$ & ${ }^{* *} 0.603-$ \\
\hline
\end{tabular}

It is evident from the previous table that there is a negative relationship between the two measures of psychological empowerment and professional burnout. The results of the study agree with the study of Pandey (2004) and the study (Pinto AL 2005). The researcher believes that this is due to the fact that the teacher who feels a high degree of psychological empowerment has a greater chance to reduce the feeling of job burnout, as he has high capabilities that enable him to face the surrounding pressures. With it, regardless of its severity, it also has a high capacity for achievement and motivation to work. All of this contributes to reducing professional job burnout.

The third question "What is the size of the correlation between the measure of self-confidence and the professional burnout scale among teachers of special education in the governorates of Gaza?" 
International Journal of Childhood, Counselling, \& Special Education (CCSE), Volume3, Issue1, Sept: 2021, pp.1-19

Table (3): Correlation coefficients between the overall score of the Self-Confidence Scale and the Occupational Occupational Burnout Scale

\begin{tabular}{llllllll}
\hline Statement & $\begin{array}{l}\text { Job } \\
\text { dissatisf } \\
\text { action }\end{array}$ & $\begin{array}{l}\text { Occupat } \\
\text { ional } \\
\text { pressure }\end{array}$ & $\begin{array}{l}\text { The } \\
\text { trend towards } \\
\text { students with } \\
\text { special needs }\end{array}$ & $\begin{array}{l}\text { Personal } \\
\text { lack of } \\
\text { achievem } \\
\text { ent }\end{array}$ & $\begin{array}{l}\text { Lack of } \\
\text { positive } \\
\text { reinforceme } \\
\text { nt }\end{array}$ & $\begin{array}{l}\text { The overall score of } \\
\text { the Occupational } \\
\text { Occupational } \\
\text { Burnout Scale }\end{array}$ \\
\hline $\begin{array}{l}\text { The overall score of } \\
\text { the Occupational } \\
\text { Burnout Scale }\end{array}$ & $.405^{* *}-0$ & $-0.41^{* *}$ & $0.41^{* *}-$ & $0.25^{* *}-$ & $0.41^{* *}-$ & $0.38^{* *}-$ \\
\hline
\end{tabular}

It is clear from the previous table that there is a negative relationship between self-confidence and professional burnout through correlational relationships, the first necessary condition for building the causal model has been fulfilled.

The study was in agreement with Darling, (2006), and Rachel,. \& Hareven (2003). This is due to the fact that working with people with special needs is considered one of the professions that create a degree of frustration among workers due to the requirements of this profession, especially that those with special groups include various categories of unusual people who suffer from motor and mental disabilities and audiovisual or multiple disabilities, as each person considers a special case that requires a special type of service, education, training and support. In addition, the low abilities and capabilities of some persons with disabilities, and the diversity and severity of their problems at times, may create among many of those working with them a feeling of frustration and a weak sense of achievement or success. Which would generate these workers a sense of psychological and professional stress and thus psychological burnout. Al-Badawi (2000) believes that psychological burnout is a psychological phenomenon that professionals are exposed to, as a result of their inability to adapt to work pressures, which leads to their feeling of inability to solve Problems, and thus a loss of interest in work, and a feeling of psychological tension while performing it. The researchers define burnout as a psychological state that causes individuals to become exhausted and tired, resulting from additional burdens, with which the individual feels unable to This is reflected in the individuals working with them, those dealing with them, and on the level of services provided to them.

The fourth question test of the study: Is there a fit between the proposed model of relationships between the study variables and the data of teachers with special needs in the Gaza governorates, as reflected by the statistical suitability indicators? To answer the seventh question, which states the following:

To research the effect of the mediating variable on the relationship between psychological empowerment and job burnout, multiple regression was used in three stages, the first stage: in which the effect of the independent variable on the mediating variable is measured, the second stage: the effect of the independent variable on the dependent variable is measured, and the third stage: the effect of the independent variable is measured. (Perfect Mediation) or correlation decreases but remains statistically significant and is considered partial mediation (Partial Mediation Baron, R., M. \&Kenny, D.A,1986) 
International Journal of Childhood, Counselling, \& Special Education (CCSE), Volume3, Issue1, Sept: 2021, pp.1-19

Table (4): Multiple regression equation: the relationship between psychological empowerment and job burnout: self-confidence is a mediating variable

\begin{tabular}{|c|c|c|c|c|c|c|c|c|c|c|}
\hline $\begin{array}{l}\text { Intermediate } \\
\text { variable }\end{array}$ & $\begin{array}{l}\text { B- } \\
\text { Beta }\end{array}$ & $\begin{array}{l}\text { The } \\
\text { error } \\
\text { Standard }\end{array}$ & $\beta$ & $\mathrm{R} 2$ & $\mathrm{R}$ & $\mathrm{T}$ & Sig & $\begin{array}{l}\text { F- } \\
\text { value }\end{array}$ & $\begin{array}{l}\text { SIG- } \\
\mathrm{F}\end{array}$ & $\begin{array}{l}\text { Durbin } \\
\text { Watson }\end{array}$ \\
\hline $\begin{array}{l}\text { Step } 1 \\
\text { Psychological } \\
\text { empowerment }\end{array}$ & 0.602 & 0.070 & 0.616 & 0.362 & ${ }^{* *} 0.602$ & 8.85 & 0.00 & 78.4 & ** & 2.02 \\
\hline $\begin{array}{l}\text { Step } 2 \\
\text { The first } \\
\text { paradigm - } \\
\text { psychological } \\
\text { empowerment } \\
\text { - career } \\
\text { burnout }\end{array}$ & 0.444 & 0.084 & 0.490 & 0.197 & **0.444 & 5.81 & 0.00 & 33.7 & ** & 0.191 \\
\hline $\begin{array}{l}\text { Step } 3 \\
\text { The second } \\
\text { model - } \\
\text { psychological } \\
\text { empowerment } \\
\text { - career } \\
\text { burnout - self- } \\
\text { confidence }\end{array}$ & 0.236 & 0.014 & 0.333 & 0.232 & **0.482 & 2.52 & 0.002 & 20.7 & $* *$ & 0.221 \\
\hline
\end{tabular}

Table (4) showed that:

The first step: It was found that the effect of multiple regression analyzes related to the ability of the psychological empowerment variable influenced selfconfidence, and the presence of $(\mathrm{R}=$ 0.602) between psychological empowerment and self-confidence, and that the square of the correlation coefficient reached $(\mathrm{R} 2=0.362)$.

The second step is that the first model is the effect of the independent variable, psychological empowerment, on the dependent variable, functional burnout, without introducing the mediating variable into the relationship. ) Beta $=0.444, \mathrm{t}=3.21$, sig $=(0.00)$

The third step: After inserting selfconfidence in the regression equation as shown in the third model, it becomes clear that the strength of the association between the two independent variables, psychological empowerment and the dependent variable, functional burnout decreased, and the change in the value of (F) was a statistically significant function, indicating the extent of the explanation of the variance $(23.3 \%)$ in the dependent variable, and since the correlation coefficient decreased and is still statistically significant, this indicates that self-confidence mediates a partial mediation of the relationship between psychological empowerment.

It is evident from the previous figure that the effect of psychological empowerment was positive on occupational burnout

It's clear that self-confidence is a mediating variable between psychological empowerment and professional job burnout, it led to a dilution of the relationship between psychological empowerment and professional job burnout.

\section{Results and Discussion}

The researchers that this result is due to the importance of self-confidence for the individual, as it gives the individual a sense of his value, and this confidence is evident in every movement and dwelling of his movements, and the person acts naturally without anxiety or fear, as his behavior is the one who rules it and not 
others .... Also, self-confidence originates from himself It has nothing to do with the people around him, and on the contrary, it is the lack of confidence that makes the person act as if he is being watched by those around him, so his movements, actions, and even opinions in some neighborhoods are contrary to his nature and anxiety becomes his primary ally in every meeting or decision-making.

This indicates the importance that the teacher in general and special education teachers are confident of themselves, their abilities and their ability to study their scientific material, which would reduce the professional career burnout they have.

Psychological burnout adversely affects teachers and their physical, psychological and social health: On the physical side, psychological burnout increases the teacher's feeling of illness, tension, high blood pressure, back pain, persistent headaches, nausea, sleep disturbances, frequent influenza and arthritis. Psychologically, it leads to a decline in self-concept, a feeling of misery and unhappiness, low self-confidence, loss of memory, feelings of sadness, helplessness, depression, resentment, frustration, irritability, anger, loss of humor, and neglect of personal priorities (Schonfeld, 2001).

Psychological burnout leads socially to the deterioration of social relations with his colleagues and students, and the teacher prefers to remain isolated and alone, as well as affects his family relations, which affects the performance of the teacher in school, as he suffers from a lack of creativity and imagination, the inability to evaluate problems and their solutions, and dissatisfaction This weakens the individual's ability to deal appropriately with rapid changes, lack of interest in the topic he is studying, and his inability to discuss students, and make the school a stimulating environment for them. And his enthusiasm for teaching weakens, as teachers who suffer from burnout usually feel that they are unable to help their students, and have negative attitudes towards

Their students and colleagues, who are unable to achieve their goals, and feel less committed to creating an appropriate teaching environment (Tashtoush et al., 2013).

\section{Suggested Research:}

The researcher proposes conducting similar future studies within the research variables to test some other factors that could affect the occupational empowerment and burnout, which the objective limits of the current research did not allow to address, including:

- The influence of individual factors such as (age, gender, marital status, experience and length of service) on both psychological empowerment, job burnout, and self-confidence.

- The effect of psychological empowerment on job burnout.

- A theoretical study that clarifies points of agreement and difference between self-confidence and related terms such as psychological empowerment and professional burnout.

- Conducting a descriptive study comparing tolerance to the study variables (self-confidence, psychological empowerment, and professional career burnout) separately between male and female special education teachers.

- Conducting a relational descriptive study between self-confidence and both psychological empowerment and job burnout among special education teachers.

- Proposing guidance programs for special education teachers on how to educational deal with children with disabilities. 
- Proposing extension programs to give teachers the skill of psychological empowerment.

\section{Recommendations:}

Based on the findings of the current study, the researcher recommends the following:

- Developing a plan by the General Administration for Guidance and Special Education in the Ministry of Education and Higher Education to prevent and limit occupational burnout, reveal its sources and its initial symptoms, and the need to address the causes that lead to manifestations of disability and despair among special education teachers and provide them with job stability and create an appropriate social and psychological atmosphere The principle of job enrichment at work can be adopted here to ensure the renewal or diversity of activities and tasks that they perform.

And get rid of routine activities at work that would generate boredom in them.

- Holding educational meetings and training courses for teachers to make teachers have the necessary experience and skills that enhance their level of empowerment and selfconfidence, in addition to qualifying professional cadres capable of providing the necessary consultations in all fields of work to address work pressures and reduce professional job burnout.

- Reducing the administrative and teaching burdens of special education teachers, in order to help them perform the tasks entrusted to them with perfection and relieve pressure on them.

- Supporting the work environment with promotional opportunities, rewards, advancement opportunities, training, and qualification to refine and empower their professional capabilities, and clarify rights, duties, tasks and expectations to avoid different differences between classes of teachers.

\section{References}

Al-Badawi, T. (2000). The degree of psychological burnout and its sources for nurses working in hospitals in Amman Governorate and the effect of some variables on that." Master Thesis (unpublished.) University of Mutah, Karak, Jordan.

Al-Batayneh, U. \& Al-Jawarneh, A. (2004). The levels of psychological burnout among teachers of special education and their relationship to some variables. The Journal of the Union of Arab Universities for Education and Psychology, 2(2).

Al-Enezi, F. (2001). The Sub-components of Self-Confidence and Shyness a Relational Study of Two Factors. Journal of Social Sciences, 29(3).

Al-Khatib, J. \& Al-Hadidi, M. (1994). Curricula and Methods of Teaching Special Education Amman: College of Educational Sciences. University of Jordan, 1st Edition.

Al-Lala, Z. \& Al-Lala, S. (2014). Psychological burnout among teachers with special needs in the Qassim region in light of some variables. The International Special Education Journal, 3 (8).

Al-Nawajhah, Z. (2016). Psychological empowerment and life orientation among a sample of primary school teachers, AlQuds Open University. Journal of Educational and Psychological Studies, 4: 283 316.

Al-Nouri, M. (2011). Measuring the dimensions of job burnout and its relationship to some demographic variables for faculty members in some 
International Journal of Childhood, Counselling, \& Special Education (CCSE), Volume3, Issue1, Sept: 2021, pp.1-19

colleges and institutes of Baghdad. Journal of Management and Economics, (86): 1-15.

Al-Otaibi, S. (2004). Ideas to enhance the empowerment of workers in Arab organizations, a scientific paper for the Fifth Administrative Conference, Arab Administrative Development Organization, Cairo.

Al-Omar, B. (2000). The relationship of motivation to work with some personal and functional variables among employees in the State of Kuwait, Journal of the Center for Educational Research, (17).

Al-Qaryouti, I. \& Al-Khatib, F. (2006). Psychological burnout among a sample of regular student teachers with special needs in Jordan. Journal of the College of Education, United Arab Emirates University, pp. 32-154.

Al-Washli, A. \& Nasser, W. (2007) Selfconfidence and some personality traits among a sample of high school students in Makkah AlMukarramah city. "Unpublished" Master's thesis, Umm Al-Qura University, Saudi Arabia.

Al-Zahrani, F. (2008). Psychological burnout and its relationship to some personality traits of women workers with special needs. Master Thesis, Saudi Arabia.

Al-Zeyoudi, M. (2007). Sources of psychological stress and psychological burnout among special education teachers in Karak governorate and their relationship to some variables. Damascus University Journal, 12 (23):189-219.

Afaneh, H. (2013). Administrative empowerment and its relationship to the effectiveness of work teams "in international NGOs operating in the Gaza Strip." Master's thesis "unpublished", Islamic University, Gaza, Palestine.

Ali, R. \& Taha, M. (2011). The role of managerial skills for managers in the organizational leadership culture dimensions. unpublished Master's thesis, Management and Economics School, faculty of Law and Administration, University of Duhok.

Ali, S. (2009). The effectiveness of a proposed counseling program for developing selfconfidence among female students of the Islamic University of Gaza, MA thesis, Islamic University, Gaza.

Andrews, A. \& Ma'ayah, A. (2008). Management with confidence and empowerment, an introduction to the development of institutions in Jordan. The modern world of books.

Awad, Y. (2009). The psychological burnout of government basic school teachers resulting from the integration of students with special needs into regular classes. An-Najah National University Journal, 24: 2495-2526.

Fatima, M. (2015). The effectiveness of psychological empowerment of teachers in the Ministry of Education in light of the theory of social learning. Islamic Azad University, Frodasht, Iran.

Masoud, S. (2010). The phenomenon of job burnout among the general administrative employees of a ministry Education and higher education in the Gaza Strip - its causes and how to treat it. "Unpublished" MA thesis, Islamic University, Gaza, Palestine.

Ministry of Education (2015). Special Education Teacher Handbook, General Administration for Guidance and Special Education, Gaza, Palestine.

Mohammed, O. \& Abdel Halim, A., (2005). Psychological burnout among teachers working with students with learning difficulties in the resource room. Umm Al-Qura University. Journal of Educational, Social and Human Sciences, Makkah Al-Mukarramah, 17(2).

Shaheen, H. (2015). Psychological empowerment and professional psychological burnout among special 
International Journal of Childhood, Counselling, \& Special Education (CCSE), Volume3, Issue1, Sept: 2021, pp.1-19

education teachers in Jordan. Journal of Educational Sciences, 2(1).

Shapira, O. \& Tsemach, S. (2014) Psychological Empowerment as Lishchinsky a Mediator Between Teachers' Perceptions of Authentic Leadership and Their Withdrawal and Citizenship Behaviors. Educational Administration Quarterly.

Shelton, S. (2002). Employees, Supervisors and Empowerment in the Public Sector: The Role of Employee Trust. Unpublished
Dissertation. North Carolina State University. U.S.A.

Tashtoush, R., Jarwan, A., Muhaidat, M., Bani, A., \& Ziyad, A. (2013). The phenomenon of psychological burnout, job satisfaction and the relationship between them among resource room teachers in Jordan. An-Najah University Journal for Research (Humanities), 27. 